\title{
Research on online marketing channel layout of luxury brands
}

\author{
Shan Wang ${ }^{1, a}$, Gang Fang ${ }^{1, b *}$ \\ ${ }^{1}$ Business School, Beijing Institute of Fashion Technology, Beijing, China
}

\begin{abstract}
Based on the background that international luxury brands have entered the Chinese market in recent years and have carried out digital operation, this paper researches the channel layout of online marketing of luxury brands in China. And this paper analyzes the domestic market environment of luxury brands from four aspects of political factors, economic factors, social factors and technical factors, and analyzes the brands marketing layout from three aspects of new media channels, e-commerce channels and social retail channels. It is found that online marketing has a positive effect on brand management in the China's market environment. Moreover, the boundaries among new media channels, e-commerce channels and social retail channels tend to be blurred. Each channel has its own advantages, and brands need to match their own positioning with channel economy.
\end{abstract}

\section{Introduction}

Luxury products originated in Louis XIV of France in the 17 th century and involved in food, fashion, decoration and other aspects. Luxury goods were born in the centralized monarchy and were used by the royal nobles at first. With the French Revolution and the British Industrial Revolution in the 18th century, capitalism prevailed in western countries, and luxury goods became the consumer goods of the middle class and above1.

Around the 21 st century, international luxury brands successively entered the Chinese market, initially opening their stores in five-star hotels, then covering high-end business districts. At the beginning of contact with luxury goods, most China consumers consume luxury goods out of social oriented purchase motivation, such as in order to highlight social status or to satisfy flaunting psychology. With the gradual popularization of luxury culture in China, the attitude of consumers towards luxury goods has changed. In 2019, the global personal luxury market grew by $4 \%$ to 281 billion Euro. Asia provided the main growth impetus for the world luxury market, and consumers in China have driven the economic growth of luxury goods in Asia. Hong Kong and its neighboring countries are the first choice for mainland consumers to purchase luxury goods. The major consumers in China market are generation $\mathrm{Y}$ and generation $\mathrm{Z}$, who have grown up and lived after the reform and opening-up and have better material living conditions. Besides, most of them are well educated and have strong ability to accept new things 2 . This provides favorable conditions for the marketing of international luxury brands in China, and provides new ideas for strengthening the growth of luxury market.

\section{Analysis of the market environment of luxury brands in China -- PEST analysis mode}

Nowadays, the Chinese market environment is completely under the background of mobile Internet, so the digital transformation of traditional brands is an inevitable choice. The development of luxury brands cannot be divorced from the macro environment, which must be taken into account in both long-term and short-term plans of brands.Therefore, it is inevitable for luxury brands to shift their marketing layout from offline to online.

\subsection{Political factors}

The operation of luxury goods is highly correlated with geopolitics, and the policies of the country or region where the operation is conducted can have a direct impact on the operation of luxury goods. In terms of the status quo of China's macro market environment, on the one hand, China's national leaders put forward anti-corruption policies, and the social oriented consumption motivation of giving luxury goods as gifts has weakened. On the other hand, China advocates international cultural exchange and attaches importance to the development of cultural industry and cultural economy. As one of the entry points for Chinese people to understand Western culture, the luxury goods industry is closely related to culture. Namely, the current macro market environment is favorable for the development of luxury goods. In addition, in recent years, China's laws have strengthened the protection of intellectual property rights, which has played a positive role in cracking down

\footnotetext{
a869209549@qq.com

b* Corresponding author: bift20130018@163.com
} 
on fake luxury goods.

\subsection{Economic factors}

The global luxury market is in recession except Asia, Europe and the United States. In the Asian market, China and Japan are the main sources of growth, and consumers have a strong response to luxury goods. There are many similarities between China's luxury consumers and Japan, and the development track of luxury industry is also similar3. The proportion of the middle class and above in China is increasing year by year, and the purchasing power of consumers is becoming stronger and stronger, and the price is no longer a factor restricting consumption. Although the income of the young group does not reach the level of the middle class, they have the concept of consumption ahead of time, and they will use installment payment software or credit card to advance consumption. In addition, luxury brands continue to extend products and expand product categories, which also provides more consumption opportunities for young customers. Luxury accessories have become a popular choice because of their ability to show off personality and taste without financial stress. In terms of channel selection of installment payment, online channels such as Alipay and Jingdong Baitiao are highly recognized by consumers. Especially for young consumers who haven't officially joined the job, it's hard for them to have their own credit cards. When they need to spend ahead of time, they always tend to choose online channels.

\subsection{Social factors}

The main consumer groups in China are different from those in other countries or regions, and there is an obvious trend of younger consumers. Young consumers like to use social media and have a unique aesthetic for fashion style. The group thinking of generation $\mathrm{Y}$ and generation $\mathrm{Z}$ is more avant-garde, they will pursue a personalized lifestyle and have a stronger desire for luxury consumption. In the third tier and below markets, luxury consumption is increasing year by year, and the long tail market of luxury goods is becoming more and more important. It is difficult for luxury brands to enter the long tail market to open physical stores for marketing, which is inconsistent with the mysterious high-end positioning of luxury goods. Online marketing channels can effectively touch the sinking market, which is an operational choice for luxury brands to improve their performance in the sinking market.

At the beginning of 2020, the COVID-19 outbreak has a negative impact on all parts of the world. People can't travel and socialize as usual, and offline physical store consumption is limited. However, the operation of luxury brands rely on offline physical stores, and the closure of physical stores at the beginning of the year has brought great impact to the luxury business. In essence, the epidemic as an objective factor has accelerated the distribution of online channels for luxury brands.

\subsection{Technical factors}

Presently, China's mobile Internet market has become mature and can provide diversified network space for brands. From the technical perspective, big data technology and digital media interaction technology can provide strong support for brand online marketing. And with the change of digital devices and the development of mobile Internet technology, consumers can also get good visual experience and interactive experience through the network. From the channel perspective, online channel has strong adjustability, which can solve the obstacles caused by time and space. There are abundant online channels in China's Internet market, and brands can choose the most suitable channel after integrating various factors. In the event of special festivals,brands can use online channels to warm up activities and formulate time-limited purchasing activities. In the event of force majeure, brands can use online channels to minimize the negative impact.

\section{Analysis on the reasons of the layout of online marketing channels for luxury brands}

The shift of luxury brand marketing from offline to online and from traditional media to new media is the common result of the demands of brands themselves and consumers. Because brand development cannot be divorced from external environment and consumer demand, accelerating its own transformation has become an inevitable choice.

\subsection{Brand transformation demand}

Luxury brands are the leaders of fashion industry, and they need to continuously meet the needs of consumers with novel and original methods. According to the AIDA model, there are five stages in a customer's purchasing process: awareness, interest, evaluation, trial and adoption, each of which determines the success of a customer's communication strategy4. In these five stages, the key is to know. Only after customers know the brand is likely to be interested in the brand, the subsequent stage is likely to proceed. In this regard, luxury brands need to expand the scope of marketing influence and bring the brand into the public eye, so that consumers can know the brand. Under the background that digital reading has gradually become the dominant one, brands must make efforts in online marketing channels. Although the mass cultural attribute of Internet media does not match the high-end and mystery of luxury goods, brands can still maintain their high-end image by adopting non discount and non price reduction strategies, and brands can also strengthen the respect and desire of ordinary consumers for brands by only interacting with high-end consumers5. 


\subsection{Consumer group behavior preference demand}

With the gradual extension of luxury brands and the continuous subdivision of product categories, luxury consumers in China show the characteristics of younger. That is, luxury goods become the choice of 20-35 year-old people to pursue fashion trends, and this group can be divided into two categories: those who have the purchasing power and those who have no purchasing power but have the desire to consume6. Young consumers tend to diversify their views on fashion, and they have unique aesthetics and opinions on luxury goods. In the aspect of fashion consumption, they began to pursue individuation and have higher acceptance of avant-garde and unique fashion products. The purpose of buying luxury goods has gradually changed from social orientation to personal orientation, and personal orientation has become the main consumption motivation.

Generation $\mathrm{Z}$ is one of the main groups of luxury consumption in China. They are deeply influenced by the development of the Internet, and their lives are extremely dependent on social media, which leads to the failure of relatively closed traditional luxury marketing mode in the Chinese market. Taking young women as an example, their understanding of luxury goods will significantly affect their consumption motivation, and their education level will also affect their attitude towards luxury goods7. Luxury brand is a high-end differentiated brand relying on business model, and its core point is commercialization. Brand needs to seek better development through profit, so the change of customer group behavior preference is enough to promote brand marketing from offline to online.

\section{Analysis of online marketing channels layout of luxury brands}

At present, social media, mobile terminals and video websites are the three mainstream platforms for luxury brands to carry out digital marketing. On the one hand, digital marketing has the advantages of strong interactivity, accurate audience, and quantifiable effect. On the other hand, it caters to consumers' behavioral preference of obtaining the latest information through the Internet8. At this stage, most luxury brands will spread brand information, maintain brand community, cultivate fans and establish positive brand image through WeChat and micro-blog accounts. Dior is a typical example of brand marketing in luxury brands by building its own new media account. In 2016, Dior tried to carry out festival marketing in WeChat account for the first time on Chinese Valentine's Eve, and 200 Diro handbags were sold out in 20 hours. Since then, Dior has been using its own new media account for innovative marketing. And up to now, Dior has not established cooperation with any third-party e-commerce in China, and has been relying on its own strength to carry out new media marketing.

\subsection{Analysis of new media channels}

\subsubsection{Own new media account}

New media marketing of luxury brands in China is mainly based on WeChat and micro-blog, in which official accounts are opened to interact with consumers. This decision is consistent with the preference of local consumers to obtain luxury brand information. According to statistics, $45 \%$ of consumers choose micro-blog to obtain information, and $32 \%$ of consumers choose WeChat to obtain information9. At this stage, most luxury brands will spread brand information, maintain brand community, cultivate fans and establish positive brand image through WeChat and micro-blog accounts. Dior is a typical example of brand marketing in luxury brands by building its own new media account. In 2016, Dior tried to carry out festival marketing in WeChat account for the first time on Chinese Valentine's Eve, and 200 Diro handbags were sold out in 20 hours. Since then, Dior has been using its own new media account for innovative marketing. And up to now, Dior has not established cooperation with any third-party e-commerce in China, and has been relying on its own strength to carry out new media marketing 10 .

\subsubsection{Third party new media account}

Third party new media accounts can be divided into social communication, video and news information, and marketing will appear in different forms in different types of accounts. The brand can also reach marketing cooperation with the new media platform official, so that the brand can be spread in the form of advertising. Tencent, as the head of China's Internet company, has a variety of online marketing platforms, and the number of groups affected by marketing is huge. Among them, WeChat's users cover all age groups. Porsche Cayenne has reached an advertising cooperation with Tencent, using a combination of multiple materials to target different precise target groups.The average Click Through Rate (CTR) is as high as $1.5 \%+$, and Cost Per Action (CPA) has been reduced by $50 \%$. In the social communication and video accounts, brand marketing is basically in the form of native advertising, narrowing the distance between luxury goods and consumers. This kind of marketing is mainly aimed at the group of generation $\mathrm{Z}$, aiming at catering to their social preferences. But at the same time, brands need to pay special attention to the fit and relevance of media types and their own brand image, so as to avoid the problems of improper audience selection and presentation 11 .

\subsection{Analysis of e-commerce channels}

According to the report on luxury products in China 2020 jointly released by Rhodes Public Relations and Precision Market Research Center, Alibaba platform currently takes the leading position in domestic luxury online sales channels. $60 \%$ of respondents said that they had bought luxury products in T-mall, Taobao or T-mall 
luxury virtual app, while the official brand website and Jingdong (hereinafter referred to as JD) ranked second and third respectively 12 .

\subsubsection{Alibaba}

On September 30, 2019, Net-A-Porter, a luxury e-commerce of Richemont group, officially opened its flagship store on the luxury platform luxury Pavilion of T-mall, which indicates that the cooperation between Alibaba and Richemont group has officially begun. The flagship store contains a full range of luxury goods, including more than 130 brands. The deep cooperation between Richemont and Alibaba can produce credit endorsement for Alibaba's luxury business, and consumers will transfer their trust to Alibaba group. In addition, Alibaba's platforms have a strong sinking ability, which can better touch the sinking market. With the rise of consumption capacity in the second, third and fourth tier cities, there are more than 200 cities with luxury consumption potential in China. Long tail demand for any luxury brand, only relying on offline stores is beyond reach.

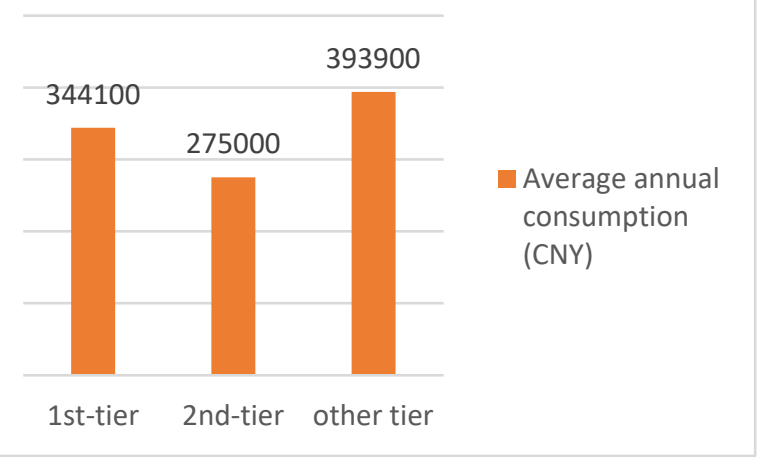

Figure 1. The average consumer spent on luxury goods over the past year

Data source: RUDER FINN. China luxury forecast 2020

Alibaba's platforms have a high national degree and user stickiness, which is conducive to the expansion of luxury brand influence and sinking marketing. In addition, Alibaba has a lot of experience in the construction and operation of live e-commerce business, which has great guiding significance for luxury live e-commerce business. In addition, the brand chose to cooperate with Alibaba also focused on its mature marketing ability. On January 9, 2020, Cartier, a jewelry and luxury brand of Richemont group, entered T-mall. Justeun clou, a new Bracelet released in tmall's super brand day on February 10, was sold out on that day, among which the limited edition of black ceramics was sold out within one minute. The marketing technology behind this comes from Alibaba's mature data analysis ability, that is, accurately targeting potential consumers according to the existing user consumption data.

\subsubsection{JD}

JD has a good fashion background and has professional service advantages in luxury brand operation. On the one hand, JD has launched JD luxury express for online high-end products, which is different from the express delivery of general goods. Express personnel are specially trained JD staff that can provide personalized delivery service for customers. On the other hand, JD has a strict protection mechanism for luxury brands. Only the official Direct stores can sell luxury goods in the platform, effectively avoiding the proliferation of fake goods on the platform. In addition, JD has a complete logistics system, which can provide favorable technical support in the whole process of luxury sales.

JD is keen on cooperating with third-party luxury goods operators. In June 2017, JD reached a strategic cooperation agreement with Farfetch, the world's leading fashion boutique shopping platform, to create a national preferred platform for online luxury shopping. In July 2018, JD invested in Secoo, an online luxury platform, to expand its influence in the fashion and luxury market. In October 2018, JD established a strategic partnership with Xinyu group, an international watch and clock retailer, to provide Chinese consumers with a new way to experience and buy the best watches in the world. In February 2019, JD's own luxury service platform TOPLIFE and Farfetch's business in China were officially merged, and luxury business became a part of JD's fashion development strategy. In addition, JD has a strategic partnership with London Fashion Week and is the exclusive retailer of London Fashion week in China.

\subsection{Analysis of social retail channels}

This paper adopts the definition of social retail in 2020 white paper on social retail in China, social retail refers to the marketing or sales mode in which brands influence consumers' purchase decisions through online social ecology13. The combination of "social" and "retail" has given birth to a new business form. The brand retail strategy has changed from traditional channel to integration of traditional channel and social channel. The development of social retail benefits from the highly developed social media platform in China. Social media has a high penetration rate in daily life, so daily life is highly related to social media. An early example of the development of social retail in China is that Sina and Alibaba reached a strategic cooperation in 2013 and began to develop social e-commerce.

In 2019, luxury e-commerce and luxury communication based on WeChat platform began to be favored by various brands. The immersion shopping mode based on WeChat applet has been widely promoted. Luxury brands combine celebrity effect with WeChat applet for limited time marketing, and use WeChat's ecological closed loop to effectively enhance the brand's influence. Consumers read fragmented in WeChat public account, browse and purchase products in WeChat applet, share with friends through instant messaging function, and finally share in social circle to complete secondary communication. 


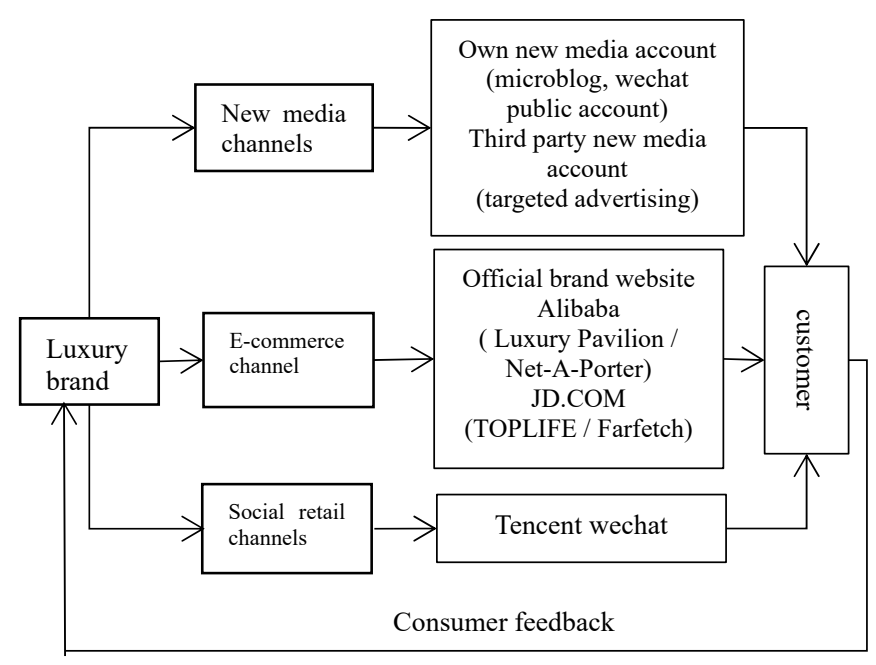

Figure 2. Online marketing process of luxury brands

\section{Conclusion}

Micro factors such as demand in the long tail market and behavior preference of generation $Z$ make online marketing become the choice of luxury brands, while the drastic changes of macro social factors force luxury brands to choose online marketing. The boundaries of new media channels, e-commerce channels and social retail channels are gradually blurred, and there is a relationship of mutual promotion among the three. Social retail is a business model developed after the combination of new media and e-commerce, which is highly consistent with the current consumer behavior preferences, and is the preferred choice of brand online marketing. Compared with offline marketing, online marketing has greater variability, covers more people, and can bring good visual experience to the audience across time and space. At present, the online marketing of luxury brands in China has not yet formed a scale. The marketing planning of most brands is still in the initial stage, and only a few brands have made some progress in online marketing. As China's Internet environment is complex and changeable, luxury brands need to define their brand positioning in online marketing to ensure the adaptability of brands and online marketing channels.

\section{Acknowledgments}

Supported by: The project of the education \& teaching reform at Beijing Institute of Fashion Technology (No.ZDJG1807); The construction program of innovation team at Beijing Institute of Fashion Technology (BIFTTD201901).

\section{References}

1. Gu Y. (2013) The change of fashion taste in Europe. J. Fashion guide, 2: 27-30.

2. Bain consulting. (2020) China's luxury market continues to grow strongly, and generation $\mathrm{Z}$ will become the main consumer force in the future. http://www.bain.com.cn/news_info.php?id=1013

3. Wang X. (2018) Analysis of the current situation, characteristics and trends of China's luxury consumer market. J. Business Economics Research, 9: 49-51.

4. Grose V. (2017) Fashion industry management: Fashion Marketing. M. China Textile Press, 146-147.

5. Shan J., Cui C.H., Wu J. (2018) Luxury brands in the digital age: Reconstruction and Prospect of perceived value. J. Management modernization, 3: 79-81.

6. Li H.T. (2014) Research on localization management of European luxury brands in the context of Chinese consumer culture. D. Shanghai International studies University, 13-16.

7. Liang Z.X. (2016) Research on young women's luxury consumption motivation. D. Harbin Institute of Technology, 56.

8. Tan X.X. (2015) Research on digital marketing strategy of fashion luxury brands based on big data. D. Beijing Institute of Fashion Technology, 8-10.

9. RUDER FINN. (2020) Report on luxury products in China 2020. https://www.ruderfinnasia.com/zh/

10. BOF fashion business review. (2020) How does Dior play with China's digital strategy. https://tpskg.duanshu.com/\#/single/9ab56b8d70684e 05b159d03c48baaf3c

11. Yang L. (2012) Application of new media in luxury marketing -- Taking Chanel brand as an example. J. News knowledge, 8: 42-43.

12. RUDER FINN. (2020) Report on luxury products in China 2020. https://www.ruderfinnasia.com/zh/

13. Tencent marketing insight $\mathrm{x}$ Boston. (2020) 2020 white paper on social retail in China. http:/www.199it.com/archives/1003650.html 